\title{
Using Swellable Polymers as Structure Directing Scaffolds in Mesoporous Titania Synthesis
}

\author{
Charalambos A. Papatryfonos, Charis R. Theocharis \\ Porous Solids Group, Department of Chemistry, University of Cyprus, Nicosia, Cyprus \\ Email: charis@ucy.ac.cy
}

How to cite this paper: Papatryfonos, C.A. and Theocharis, C.R. (2018) Using Swellable Polymers as Structure Directing Scaffolds in Mesoporous Titania Synthesis. Materials Sciences and Applications, 9, 211-227.

https://doi.org/10.4236/msa.2018.92014

Received: November 17, 2017

Accepted: February 2, 2018

Published: February 5, 2018

Copyright ( 92018 by authors and Scientific Research Publishing Inc. This work is licensed under the Creative Commons Attribution International License (CC BY 4.0).

http://creativecommons.org/licenses/by/4.0/

\begin{abstract}
This paper presents a novel synthesis of well characterized nanoporous materials. The development of mesoporous $\mathrm{TiO}_{2}$ with the use of crosslinked polymer network as structure and surface texture directing agent is reported in this study. Randomly cross-linked DMAEMA-50-PEGMA-50-EGDMA1 was synthesized by radical polymerisation to be used as removable scaffold. The resulting materials were characterized by powder X-ray diffraction (pXRD), nitrogen adsorption, scanning electron microscopy (SEM), Fourier transform infrared spectroscopy (FT-IR), differential scanning calorimetry (DSC) and thermogravimetric analysis (TGA). The synthesized oxides morphology was strongly influenced by the polymer network used as removable scaffold. The modified materials exhibited a narrower pore size distribution and marginally higher specific surface area compared to the unmodified samples. The scaffold cross-linking ratio was also found to have a significant effect on the synthesized materials polymorph. The modification has a strong effect on the titania polymorph as the anatase-rutile transformation was observed only for the modified titania samples.
\end{abstract}

\section{Keywords}

Titania, Organic Scaffold, Template, Mesoporous, Porosity Modification

\section{Introduction}

Titania-based materials have rapidly attracted great attention due to important applications in photo-catalysis [1] [2] [3] [4] [5], chemical sensors [6] and solar cells [7] among many others. These materials find significant applications in a wide variety of fields. Most of their useful functions depend not only on the 
composition but also strongly on the structure and morphology of the materials. Hence the synthesis of these materials has been attracting intense interest and great efforts have been made to obtain metal oxide structures with fabricated morphologies [8]-[13].

Previous work has been conducted in the porous solids research group of the University of Cyprus, including the synthesis of porous oxides by investigating methods of improvement of these materials properties. These porous metal oxide modifications include the synthesis of mixed ceria with transition metals [8] [9], mixed metal oxide phases with the use of different solvent systems [10] and the use of templates such as humic acid [11] and CTAB [12] [13]. The results of this previous work showed that the use of these modifications played an important role in the formation of the target products and improved their structural characteristics. Many other materials have also been used as supports in several reports in literature for the synthesis of porous oxides, proving that their use altered and improved the synthesized materials surface properties and that presaged that this process would possibly lead to novel porous materials.

This paper proposes a novel strategy for the design in synthesis of mesoporous materials with the use of swellable polymer networks used as scaffolds. Previous reports use different materials that have a templating effect towards the precursor. In such cases the organic material acts as central formation about which the precursor moieties organize and by this way a material influenced by the template is formed [14]. In this paper, we show a novel path by using a removable scaffold used both as a structure and surface texture directing agent, influencing the resulting material and at the same time acting as a reaction vessel.

Many reports in literature in regards to the synthesis of titania with the use of templates show the growing interest in new synthesis methods for this material over the last years. Additionally, it is in many cases shown that the use of organic supports enhanced the synthesized materials properties by manipulating their porous structure and surface characteristics. In particular, $\mathrm{TiO}_{2}$ fibres were reported to be fabricated under autogenous pressure, using activated carbon fibres as templates with no consumption of organic solvent providing an environmentally friendlier synthesis route in comparison to using organic solvents [15]. Triblock copolymer $\mathrm{HO}\left(\mathrm{CH}_{2} \mathrm{CH}_{2} \mathrm{O}\right)_{20}\left(\mathrm{CH}_{2} \mathrm{CH}\left(\mathrm{CH}_{3} \mathrm{O}\right)_{70}\left(\mathrm{CH}_{2} \mathrm{CH}_{2} \mathrm{O}\right)_{20} \mathrm{H}\right.$ (Pluronic $\mathrm{P}-123)$ was also used successfully as template material to synthesize semicrystallized mesoporous $\mathrm{TiO}_{2}$ thin films with hexagonal mesoporous structure [16]. Activated carbon templates were also reported to be used as templates in a sol-gel synthesis employing titanium (IV) tetraisopropoxide (TIP) as a precursor where very high surface area titania was obtained possessing micropores and mesopores [17]. The synthesis of titania with improved photocatalytic activity on the degradation of a methyl Rhodamine $\mathrm{B}(\mathrm{RhB})$ was reported with modified titania prepared by a controlled hydrothermal precipitation using resorcinol-formaldehyde resin spheres as templates in aqueous solution [18]. Improved catalytic activity was also reported with the use of plants skins as templates and 
specifically the skins of tomatoes, bulb onions, grapes, and garlic bulbs were used in a mesoporous titania synthesis with titanium tertraisopropoxide (TTIP) as a precursor. All of the synthesized mesoporous titania samples exhibited similar morphologies to those of the original templates confirming the template effect on the morphology and photocatalytic properties of the synthesized material [19].

Porous titania which had the anatase structure and high surface area was synthesized with the use of cellulose nanocrystals as template [20]. Mesoporous titania can also be synthesized with the use of more than one templates with the combination of pluronic P123 and poly ethylene glycol templates and acetic acid as the hydrolytic retardant with extremely high crystallinity achieved during synthesis process. The resulting material was reported to have remarkable thermal stability and improved photocatalytical properties [21]. The preparation of aligned titania nanowires was also reported with the use of carbon nanotube/ hydrogel composite template [22].

The use of these templates played an important role in the formation of the precipitates and improved the structural characteristics of the synthesized materials. In this work, a novel alternative methodology was implemented with the use of swellable polymer networks as removable scaffolds where the material was synthesized into the scaffolds net-like structure using the polymer network itself as both a reaction vessel and a structure directing agent.

\section{Experimental}

\subsection{Materials}

The chemical reagents used were reagent grade (Aldrich Germany) and were used without further purification. The compounds used were, 2 (dimethylamino) ethyl methacrylate (DMAEMA, 98\%), poly(ethylene glycol) methylether methacrylate (PEGMA 98\%, $\mathrm{M}_{\mathrm{w}} 300 \mathrm{~g} / \mathrm{mol}$ ), the radical initiator 2,2-azobis (isobutyronitrile) (AIBN) and ethylene glycol dimethacrylate (EGDMA 98\%), titanuim (IV) butoxide $\mathrm{Ti}\left(\mathrm{OCH}_{2} \mathrm{CH}_{2} \mathrm{CH}_{2} \mathrm{CH}_{3}\right)_{4} 97 \%$ and ethanol analytical grade $\geq 99.8 \%$. Tetrahydrofuran (THF) was purchased from Scharlau Spain.

\subsection{Synthesis of Polymer Network DMAEMA-50-PEGMA-50-EGDMA}

For the preparation of randomly cross-linked network of DMAEMA $_{50}$-coPEGMA $_{50}$-Co-EGDMA $1,98 \mathrm{mg}\left(6 \times 10^{-3} \mathrm{~mol}\right)$ of the radical initiator 2, 2-azobis (isobutyronitrile) (AIBN), $5 \mathrm{ml}(4.68 \mathrm{~g}, 0.03 \mathrm{~mol})$ of the monomer 2-(dimethylamino)ethyl methacrylate (DMAEMA), $8.5 \mathrm{ml}$ ( $8.93 \mathrm{~g}, 0.03 \mathrm{~mole}$ ) of the monomer poly(ethylene glycol) methylether methacrylate (PEGMA), $0.11 \mathrm{ml}$ $\left(0.12 \mathrm{~g}, 6 \times 10^{-4} \mathrm{~mol}\right)$ of the cross-linker ethylene glycol dimethacrylate (EGDMA) and $31.7 \mathrm{ml}$ tedrahydrofuran (THF) were added in a $100 \mathrm{ml}$ round bottom flask under vigorous stirring placed in an oil bath at $70^{\circ} \mathrm{C}$ for $24 \mathrm{~h}$ until the polymer gel was formed. The resulting polymer gel was dried under vacuum at $60^{\circ} \mathrm{C}$ for $48 \mathrm{~h}$. 


\subsection{Modified Titania Preparation}

Figure 1 shows schematically the structure of the cross-linked polymer network DMAEMA- ${ }_{50}$-PEGMA- ${ }_{50}-$ EGDMA $_{1}$. As can be seen, the presence of cross-links causes loops of the chains to be formed, creating an internal void, in which solvent molecules can be inserted, leading to the swelling. This creates the space in which the precipitation reaction can take place. By changing the proportion of cross-linker used, the size of the loops can be controlled, and thus the available space. In order to assure that the precipitation was held inside the scaffold and not on its surface, synthesis conditions were employed to provide slow precipitation for the $\mathrm{TiO}_{2}$ to assure that both the precursor and the precipitating agent were diffused inside the gels net like structure.

Titanium (IV) butoxide was diluted in anhydrous ethanol (10\% $\left.\mathrm{Ti}^{4+} / \mathrm{Ethanol}\right)$. The polymer gel was dispersed in $60 \mathrm{ml}$ of the solution for $24 \mathrm{~h}$ under moderate stirring. The swollen gels were washed with anhydrous ethanol in order to remove any precursor traces left outside the gels volume. After the swollen scaffold was washed, it was dispersed in water/ethanol 33\% mixture for $24 \mathrm{~h}$ and a precipitate was formed inside the gels structure giving the gel a white colour forming the "as-prepared sample". The resulting "as-prepared sample" was washed several times with ethanol/water mixtures and dried under vacuum at $60^{\circ} \mathrm{C}$ overnight. Then the product was calcined at $500^{\circ} \mathrm{C}$ for $3 \mathrm{~h}$ with a heating rate of $6^{\circ} \mathrm{C}$ $\mathrm{min}^{-1}$ and a white solid was obtained. The same procedure was carried out without the use of scaffold so as to obtain the "unmodified $\mathrm{TiO}_{2}$ ". The experimental procedure is illustrated in Figure 2.

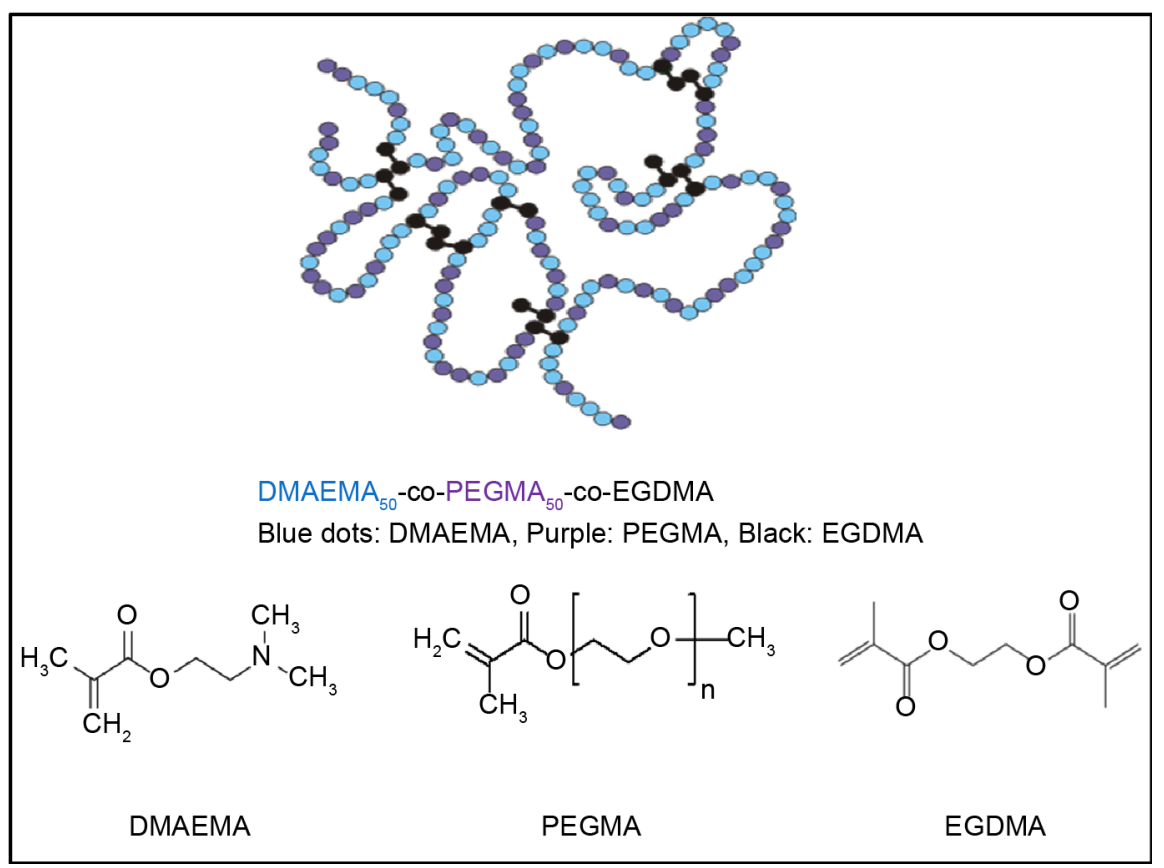

Figure 1. Randomly cross linked gel DMAEMA ${ }_{50} \mathrm{PEGMA}_{50} \mathrm{EGDMA}_{1}$ used as removable scaffold. DMAEMA: 2-(dimethylamino) ethyl methacrylate, PEGMA: poly(ethylene glycol) methylether methacrylate, EGDMA: ethyleneglycol dimethacrylate. 


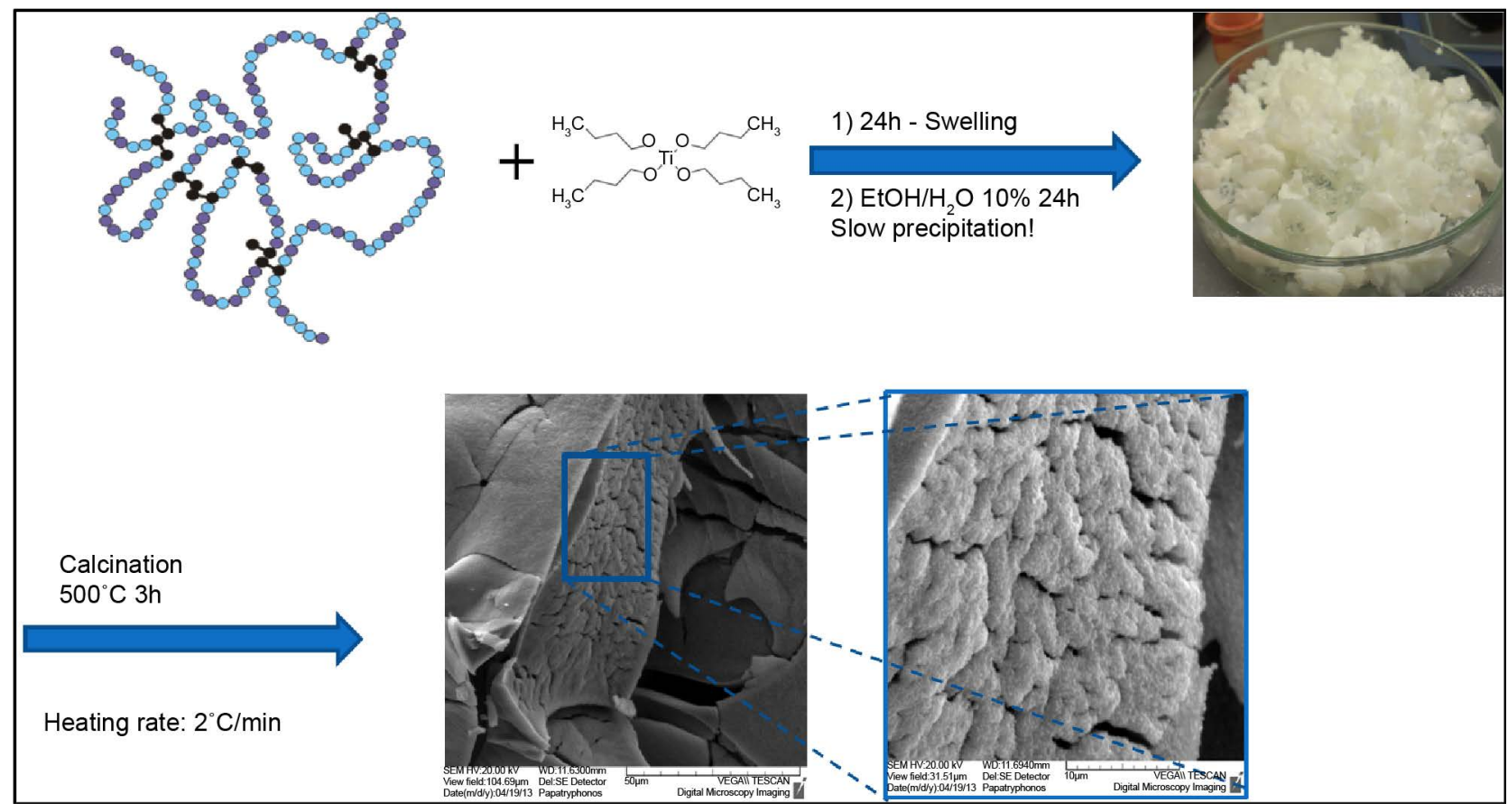

Figure 2. The experimental procedure for the synthesis of modified titania.

\subsection{Characterization}

Nitrogen adsorption isotherm measurements were carried out at $77 \mathrm{~K}$ using an ASAP 2010 Micrometrics apparatus. The samples were degassed prior to the measurements at $393 \mathrm{~K}$ for $24 \mathrm{~h}$. The BET equation was used to calculate the specific surface areas, while pore size distributions were estimated using density functional theory (DFT) methods using the supporting DFT-plus software employing a slit shaped pore model (meaning a pore length which is much longer than the other two dimensions. Scanning Electron Microscopy images were obtained to examine the materials morphology with the use of a JEOL JSM-5600 instrument. The thermal stability was studied by thermogravimetric analysis (TGA) using a Shimadzu apparatus. The measurements were carried out in air up to $1073 \mathrm{~K}$ and the heating rate was $6 \mathrm{~K} \cdot \mathrm{min}^{-1}$. Differential scanning calorimetry (DSC) was further used, using a model Q1000 by Thermal Instruments with a heating rate of $6 \mathrm{~K} \cdot \mathrm{min}^{-1}$ in the temperature range of $313-873 \mathrm{~K}$. FTIR measurements were performed using a Shimadzu spectrometer (FTIR-8501) with $\mathrm{KBr}$ powder as diluent. For the polymer networks, ATR-FTIR was used. Powder $\mathrm{X}$ ray diffraction measurements were carried out on a Shimadzu 6000 diffractometer using $K \alpha$ radiation $(\lambda=0.15478 \mathrm{~nm})$.

\section{Results and Discussion}

The adjustment of the proper calcination conditions was crucial in order to achieve the successful and complete removal of the scaffold. The calcination temperature should be high enough to achieve the clean removal of the scaffold, but at the same time sintering of the synthesized materials needs to be avoided as 
this would reduce the specific surface area and increase the particle size of the product. Additionally, the material could lose its initial scaffold-fabricated characteristics due to the extensive crystallization. In order to achieve the optimal calcination conditions and to confirm the removal of the scaffold, the materials were characterized by thermogravimetric analysis (TGA/DSC) as shown in Figure 3. The analysed samples were the as synthesized $\mathrm{Gel}-\mathrm{TiO}_{2}$ composite and the DMAEMA $_{50}$ - ${ }^{-}$PEGMA $_{50}$-co-EGDMA 1 used as scaffold. In regards to the polymer network used as scaffold, the $8 \%$ weight loss below $200^{\circ} \mathrm{C}$ is attributed to the loss of residual solvent and tightly adsorbed water corresponding to the endothermic peaks below $200^{\circ} \mathrm{C}$ as shown in the DSC plot. At temperature range from $270^{\circ} \mathrm{C}-500^{\circ} \mathrm{C}$, an $80 \%$ weight loss observed, attributed to the combustion of the organic scaffold with the complete removal at temperatures of about $580^{\circ} \mathrm{C}$ with a weight loss of about $7 \%$. This is also confirmed by the strong exothermic peak at the DSC plot appearing at $270^{\circ} \mathrm{C}$ with a maximum at $370^{\circ} \mathrm{C}$. The as synthesized modified gel- $\mathrm{TiO}_{2}$ follows a similar weight loss pattern up to $550^{\circ} \mathrm{C}$ which confirms the removal of the organic scaffold.

Based on the TGA/DSC trace and the $\mathrm{N}_{2}$ adsorption measurements (to confirm the unblocking of the pores) for the as synthesized $\mathrm{Gel}_{-} \mathrm{TiO}_{2}$ samples, the optimal calcination conditions were determined. For the removal of the organic scaffolds, the samples were calcined at $500^{\circ} \mathrm{C}$ for $3 \mathrm{~h}$ with a heating rate of $6^{\circ} \mathrm{C} / \mathrm{min}$.

The crystallite size and the polymorph for each of the synthesized samples were determined by powder XRD. Figure 4 shows the diffraction patterns of the as synthesized $\mathrm{Gel}-\mathrm{TiO}_{2}$ and unmodified $\mathrm{TiO}_{2}$ after calcination at $500^{\circ} \mathrm{C}$ for $3 \mathrm{~h}$. As can be inferred from the diffractograms, the diffraction peaks in the case of the unmodified sample match those of $\mathrm{TiO}_{2}$ anatase while for the modified titania samples, a mixed phase of anatase/rutile $\mathrm{TiO}_{2}$ is present. Additionally, no

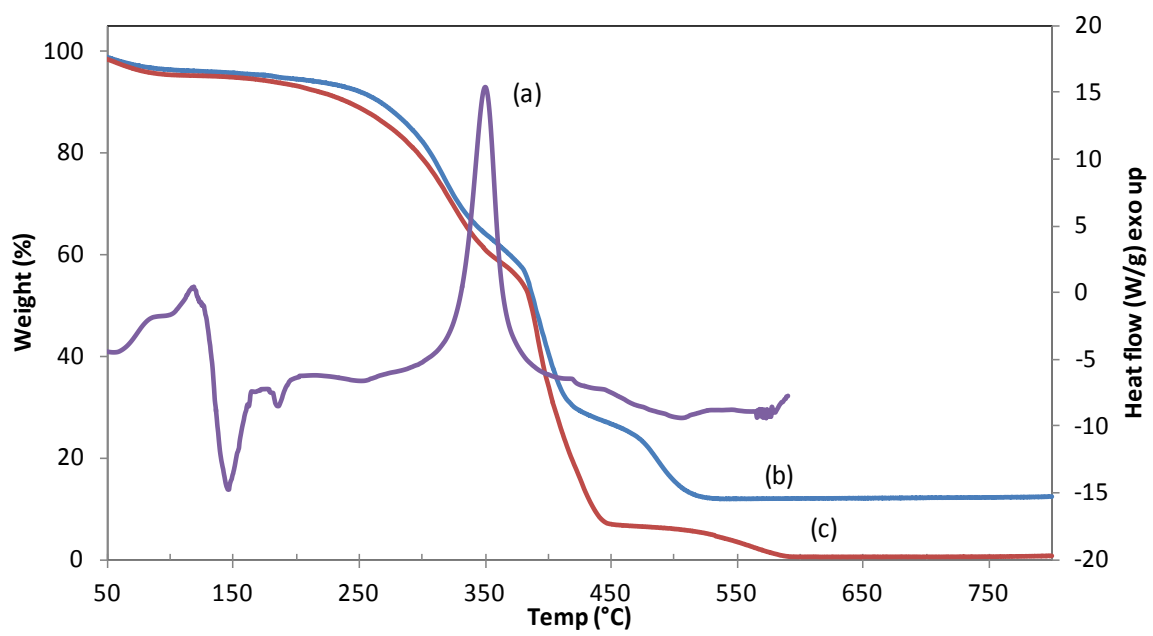

Figure 3. TGA/DSC analysis of Modified titania before calcinations and cross-linked polymer network DMAEMA ${ }_{50}$-CoPEGMA $_{50}$-co-EGDMA 1 used as removable scaffold: (a) DSC of $\mathrm{TiO}_{2}$ /scaffold, (b) TGA of $\mathrm{TiO}_{2}$ /scaffold, (c) TGA of scaffold. TGA: Thermogravimetric analysis, DSC: Differential scanning calorimetry. 
peaks, characteristic of other impurities are present which confirms the complete removal of the organic scaffold during the calcination process and that the synthesized titania material was of high purity.

Figure 5 shows the XRD patterns of modified $\mathrm{TiO}_{2}$ using the polymer network as scaffold with cross-linker concentration varying from $1 \%$ to $4 \%$. It can be seen that the rutile polymorph content is increasing with increasing cross-linking up to $4 \%$. The peaks at about $2 \Theta=25,37,38,38.5,48,54,55,63$, 69 and 70 degrees on the X-Ray diffractograms shown in Figure 4, correspond to reflections (101), (103), (004), (112), (200), (105), (211), (118), (116) and (220) of the titania anatase phase respectively. Peaks at $2 \Theta=27,36,41.5,54.5$ and 56.5 degrees correspond to diffraction from the (110), (101), (111), (211) and (220) planes respectively indicating $\mathrm{TiO}_{2}$ in rutile phase [23]. The average crystallite sizes were calculated by the Debye-Scherrer equation as represented in Table 1. As it can be seen, the rutile crystallite size is larger than the anatase

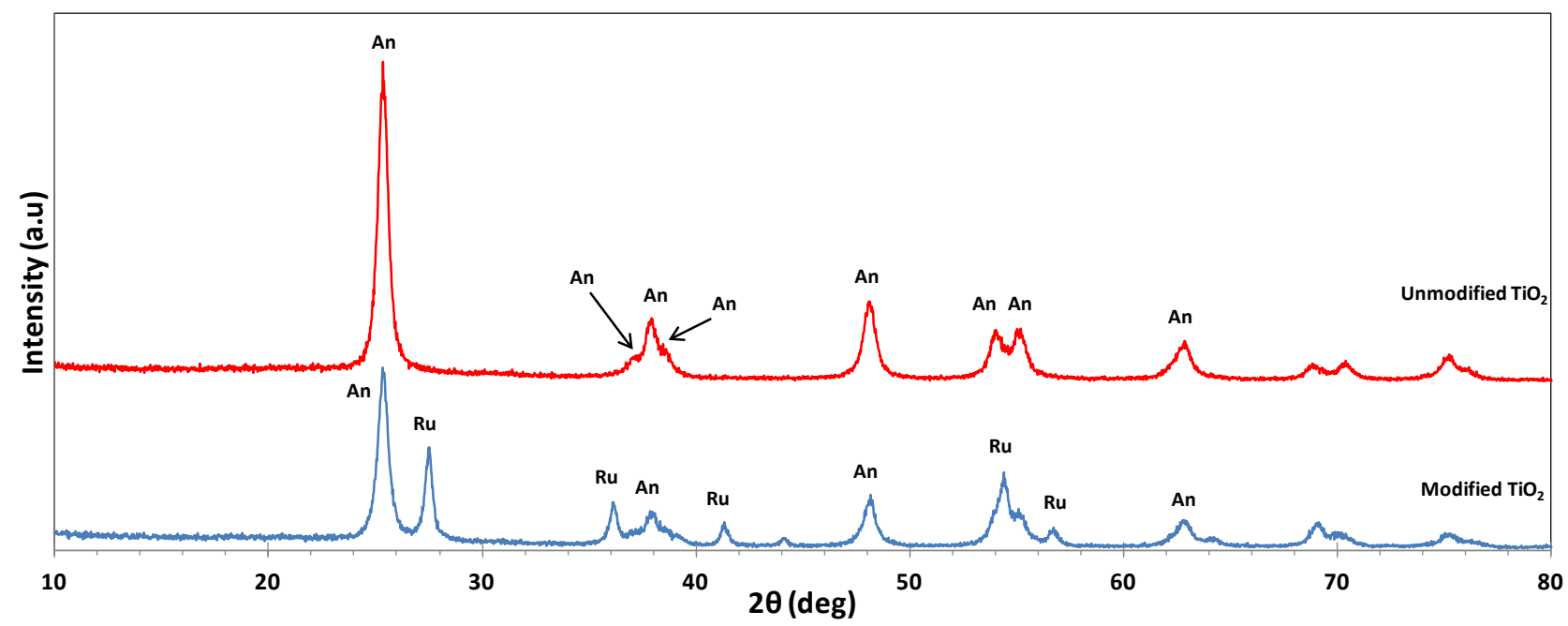

Figure 4. XRD diffractograms of unmodified and modified titania with $1 \%$ crosslinker after calcinations at $500^{\circ} \mathrm{C}$ for $3 \mathrm{~h}$.

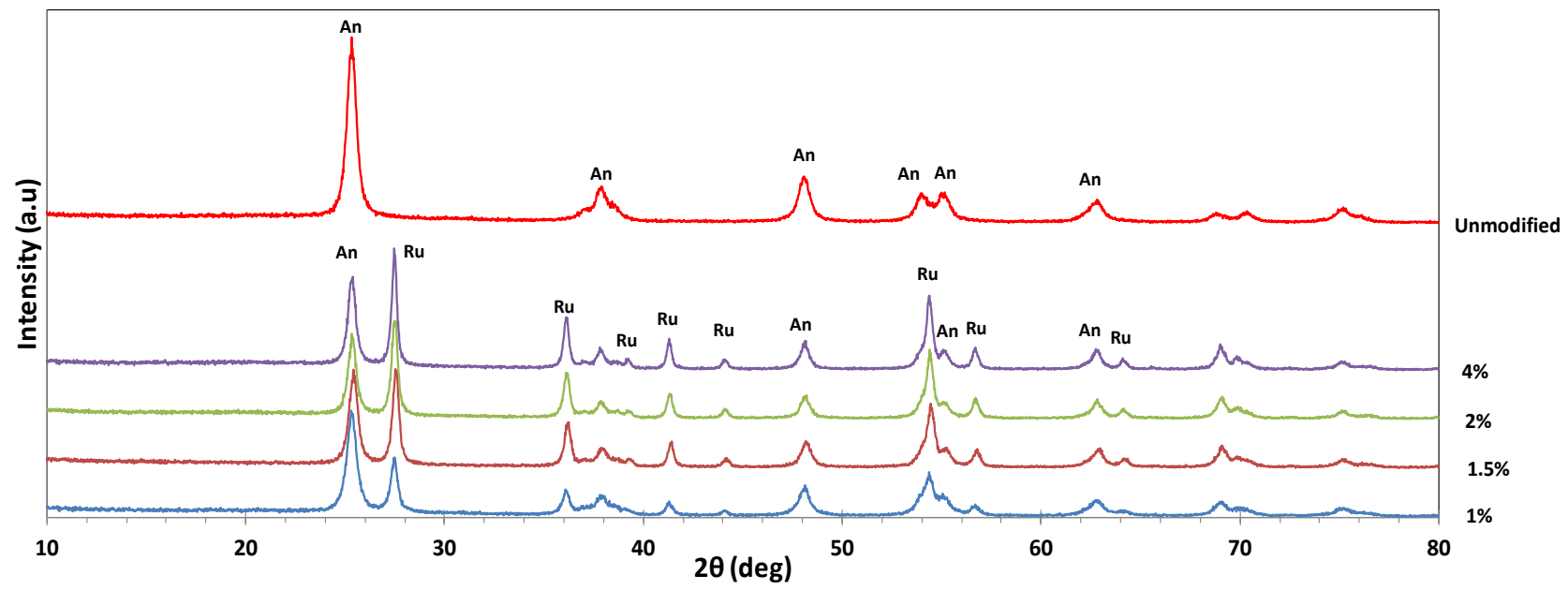

Figure 5. XRD diffractograms of modified titania with the use of scaffold with varying cross-linker percentage and diffractogram of unmodified titania. 
Table 1. Specific surface area, pore size distribution, mean pore width and crystallite size of titania synthesized with the use of scaffold with different cross-linking calcined at $500^{\circ} \mathrm{C}$ for $3 \mathrm{~h}$.

\begin{tabular}{cccccc}
\hline $\begin{array}{c}\text { Crosslinker } \\
\text { Content }(\%)\end{array}$ & $\begin{array}{c}\text { Surface Area }^{\mathrm{b}} \\
\left(\mathrm{m}^{2} / \mathrm{g}\right)\end{array}$ & $\begin{array}{c}\text { Pore Volume }^{\mathrm{c}} \\
\left(\mathrm{cm}^{3} / \mathrm{g}\right)\end{array}$ & $\begin{array}{c}\text { Crystallite size }^{\mathrm{a}} \\
(\mathrm{nm}) \text { Anatase }\end{array}$ & $\begin{array}{c}\text { Crystallite size }^{\mathrm{a}} \\
(\mathrm{nm}) \text { Rutile }\end{array}$ & $\begin{array}{c}\text { Mean Pore } \\
\text { Width }(\mathrm{nm})\end{array}$ \\
\hline $1 \%$ & 47 & 0.085 & 14 & 18 & 8 \\
$1.5 \%$ & 32 & 0.076 & 16 & 22 & 9 \\
$2 \%$ & 27 & 0.09 & 18 & 23 & 12 \\
$4 \%$ & 27 & 0.1 & 19 & 28 & 12 \\
Unmodified & 31 & 0.14 & 14 & - & broad 40 \\
\hline
\end{tabular}

${ }^{a}$ Calculated by the Scherer equation. ${ }^{b} \mathrm{BET}$ surface area calculated from the linear part of the BET plot. ${ }^{\mathrm{E} E s-}$ timated using the desorption branch of the isotherm.

crystallite size for the corresponding synthesis conditions. Presumably, the scaffolds ability to promote the mixed anatase-rutile titania phase could be attributed to the steric hindrance caused by the scaffolds net-like formation as the crystallization takes place in the voids formed by the loops of the polymer networks. It is noted that rutile is the polymorph with the higher density ( 4.25 $\left.\mathrm{g} \cdot \mathrm{cm}^{-3}\right)$ compared with anatase $\left(3.89 \mathrm{~g} \cdot \mathrm{cm}^{-3}\right)$ (Hanaor and Sorrell, 2011), as obviously crystallization of the dense phase is favoured by a confined space environment. Increase of the cross-linker content leads to a lower degree of swelling, and presumably reducing the space available for the crystallization process. These results suggest that the mechanism by which the scaffold influences the synthesis is not through an effect on the crystallite size, which would impact upon the surface area, but on the way crystallites assemble to form the particles.

The $\mathrm{N}_{2}$ adsorption isotherms and pore size distributions of unmodified samples in comparison with the corresponding modified materials using $1 \%$ cross-linker calcined at $500^{\circ} \mathrm{C}$ for $3 \mathrm{~h}$ are shown in Figure 6 and Figure 7.

As can be seen in Figure 6, the unmodified material exhibits a type II isotherm, with an $\mathrm{H} 3$ hysteresis loop indicating the presence of pseudopores, whilst in the case of modified titania the isotherm was of type IV, with an $\mathrm{H} 2$ hysteresis loop, showing the difference between in the surface texture of these two materials. The BET surface area of the modified sample was $47 \mathrm{~m}^{2} / \mathrm{g}$, as shown in Table 1 , which was marginally higher compared to the pristine sample with surface area of $31 \mathrm{~m}^{2} / \mathrm{g}$. From Figure 7, it can be seen that the pore size distribution of the modified material was much narrower compared to the pristine titania showing that the modification is responsible for a more organised mesoporous structure of the synthesized titania. The source of porosity in the materials prepared in the gel matrix is the way crystallites organise in the primary and secondary particles, and not from the crystal structure, as is the case for zeolites. However, repeated measurements of the nitrogen isotherms on separate samples give the same results, indicating these to be real pores, and not due to aggregation. The pristine and modified material possessed a pore volume of $0.14 \mathrm{~cm}^{3} / \mathrm{g}$ 


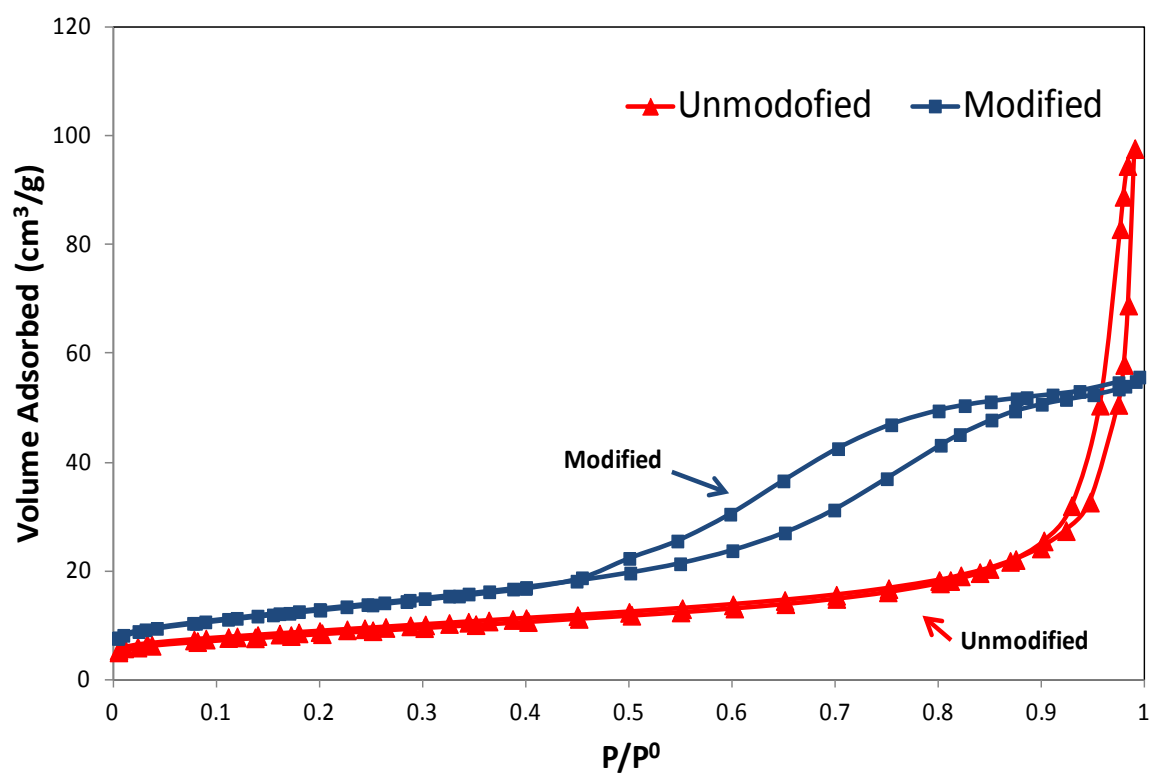

Figure 6. Comparison of the modified and unmodified adsorption/desorption $\mathrm{N}_{2}$ isotherms $\mathrm{TiO}_{2}$. Scaffold crosslinking $1 \%$.

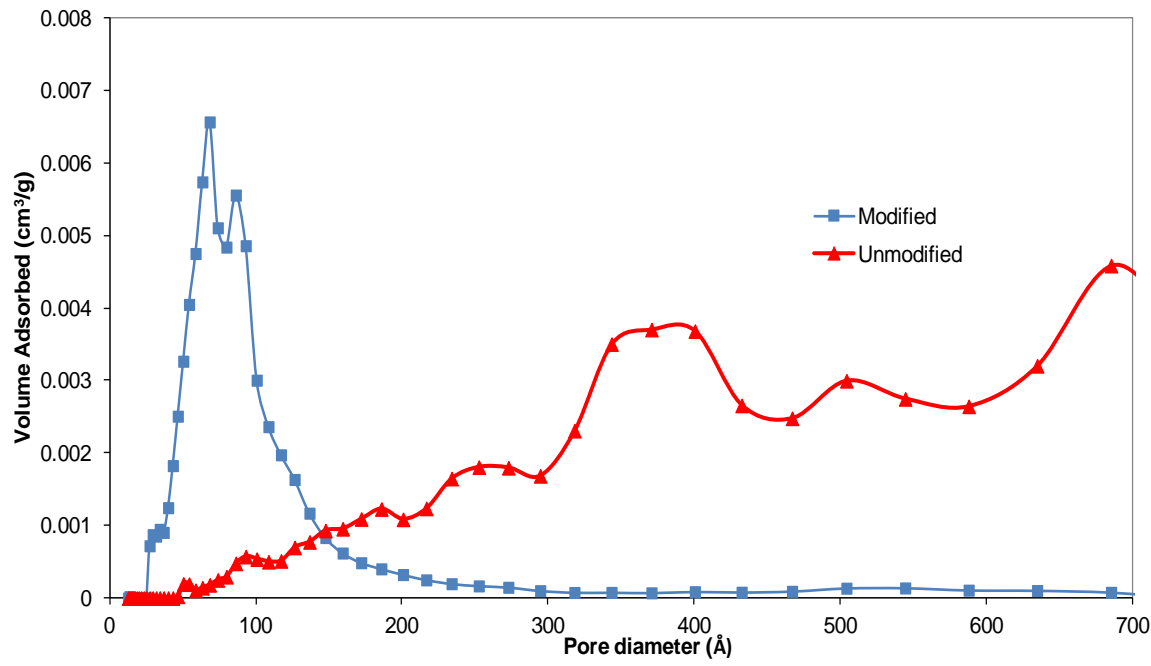

Figure 7. Comparison of pore size distribution between modified and unmodified titania prepared with the use of scaffold with $1 \%$ crosslinking after calcinations at $500^{\circ} \mathrm{C}$ for $3 \mathrm{~h}$.

and $0.085 \mathrm{~cm}^{3} / \mathrm{g}$ respectively. BET (Brunauer-Emmett-Teller) equation was used in order to determine the specific surface area from the $\mathrm{N}_{2}$ adsorption measurements [24] shown in Table 1. Figure 8 and Figure 9 show the $\mathrm{N}_{2}$ adsorption isotherms and pore size distributions respectively of modified titania synthesized with the use of polymer network as scaffold with different degrees of cross-linking. The nitrogen adsorption isotherm for the $1 \%$ cross-linker sample presented in Figure 6 and repeated here for comparison, is of type IV in the IUPAC classification indicating the presence of mesopores. The isotherms for the samples prepared from gels with higher cross-linker content were of type II, as was the case for the unmodified sample. However, the hysteresis loop moved 


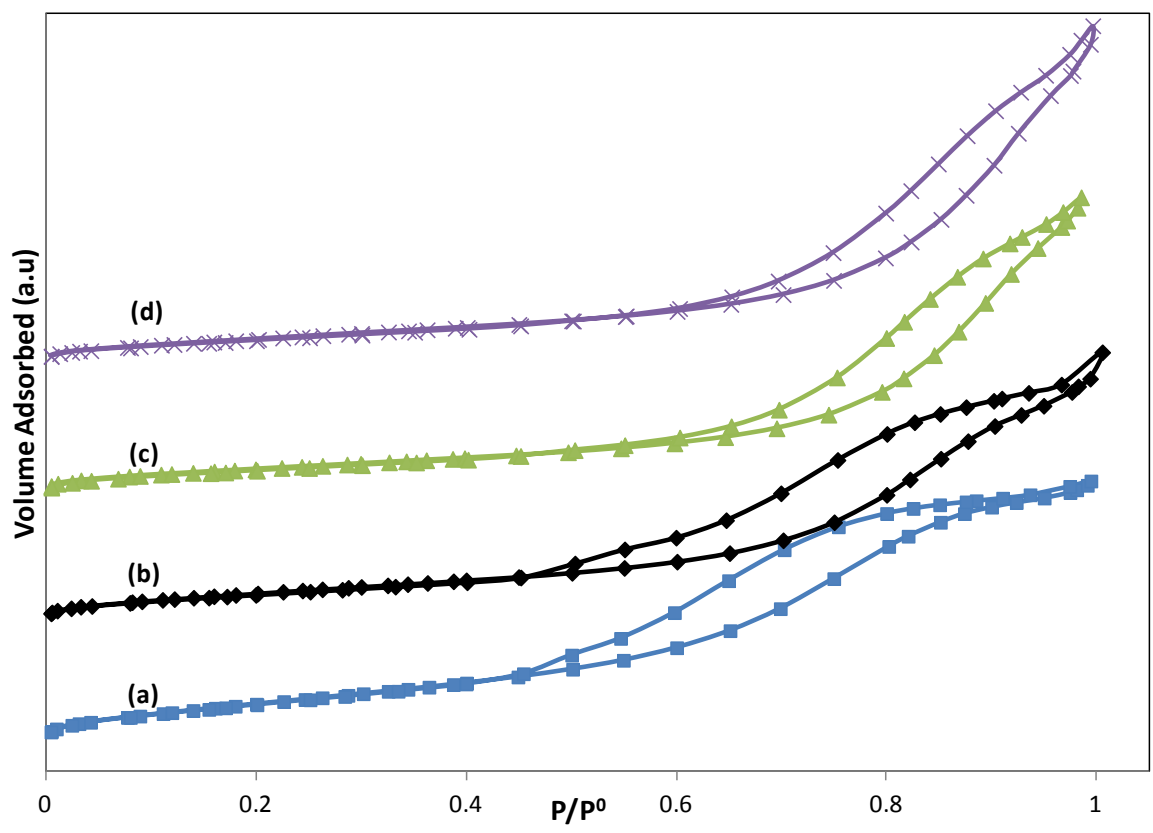

Figure 8. $\mathrm{N}_{2}$ adsorption/desorption isotherms of modified titania with $1 \%-4 \%$ crosslinking after calcinations at $500^{\circ} \mathrm{C}$ for $3 \mathrm{~h}$ : (a) $1 \%$, (b) $1.5 \%$, (c) $2 \%$, (d) $4 \%$.

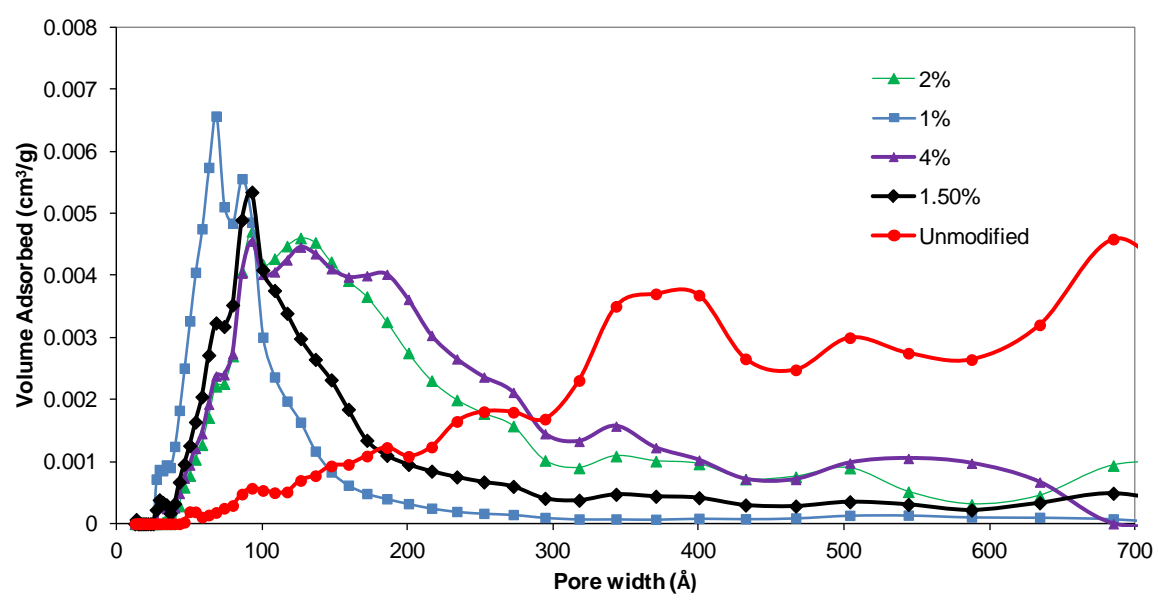

Figure 9. Pore size distribution of titania prepared with the use of polymer network DMAEMA $_{50}$-coPEGMA -co-EGDMA $_{1}$ as scaffold with different degrees of crosslinking and the unmodified titania after calcinations at $500^{\circ} \mathrm{C}$ for $3 \mathrm{~h}$.

towards higher partial pressures with increasing cross-linker content. The inflection point moves to higher partial pressures indicating a widening of pore diameter, as confirmed by the pore size distribution presented in Figure 9, showing increased pore diameter with increasing cross-linker percentage from $1 \%$ to $2 \%$.

The texture of the material is influenced by the structure of the scaffold, and in particular the distance between the cross-linking moieties, and therefore it is expected that higher cross-linking will result in a product with a more open porous structure and increased average pore diameter. The results obtained in $\mathrm{N}_{2}$ adsorption measurements and XRD measurements are summarised in Table 1. 
Examination of the data in Table 1, suggests that increasing the cross-linker content to $1.5 \%$ and up to $4 \%$, leads to samples with BET surface areas similar to those of the pristine sample, whilst keeping the pore size distribution narrower, and the pore system better organised than for the pristine sample. Comparing the pristine sample with that prepared in the presence of the $1 \%$ cross-linker Gel, indicated that the crystallite size is similar for both samples, but the pore size distributions are widely different, suggesting that crystallization in the confined space provided by the scaffold, resulted in a different organization of the crystallites, resulting in different textures.

In order to assess the structural properties of the synthesized samples and to determine the functional groups present FTIR spectroscopy was used. The spectra were obtained in the wavelength region of $4000-500 \mathrm{~cm}^{-1}$. Figure 10 shows the FTIR spectra of polymer network DMAEMA- ${ }_{50}-\mathrm{PEGMA}_{50}-\mathrm{EGDMA}_{1}$ and synthesized composite $\mathrm{TiO}_{2}$-Scaffold prior to calcination. The presence of $\mathrm{Ti}-\mathrm{OH}$ stretching vibration is confirmed by the broad band near $3440 \mathrm{~cm}^{-1}$ [19]. Bands at $2935 \mathrm{~cm}^{-1}$ and $2810 \mathrm{~cm}^{-1}$ correspond to the $\mathrm{C}-\mathrm{H}$ stretching of methyl groups and $-\mathrm{CH}_{2}-$ groups forming the backbone of the organic scaffold. The bands at $2760 \mathrm{~cm}^{-1}$ appear due to the $\mathrm{C}-\mathrm{H}$ stretching of $-\mathrm{N}\left(\mathrm{CH}_{3}\right)_{2}$ group [25] [26]. The band at $1720 \mathrm{~cm}^{-1}$ indicates the presence of $\mathrm{C}=\mathrm{O}$ ester group and the band at $1630 \mathrm{~cm}^{-1}$ shows the presence of surface adsorbed water. Additionally, the band at $1445 \mathrm{~cm}^{-1}$ corresponds to $\mathrm{CH}_{2}$ bending vibration. The $\mathrm{C}-\mathrm{H}$ and $\mathrm{C}-\mathrm{O}-\mathrm{C}$ stretching bands of $-\mathrm{OCH}_{2} \mathrm{CH}_{2}-$ are shown at 2865 and $1100 \mathrm{~cm}^{-1}$ respectively [25] [26]. The band at $500-800 \mathrm{~cm}^{-1}$ was assigned to Ti-O-Ti asymmetric stretching [19] [27] [28]. The FTIR spectrum of the modified titania after calcination is shown in Figure 11. As it can be seen, there are no bands associated with the organic scaffold therefore it is confirmed that the scaffold was removed. However, small band at $1390 \mathrm{~cm}^{-1}$ indicates that there was a small quantity of residual carbon present. The peaks shown at $1638 \mathrm{~cm}^{-1}$ and $3440 \mathrm{~cm}^{-1}$ indicate

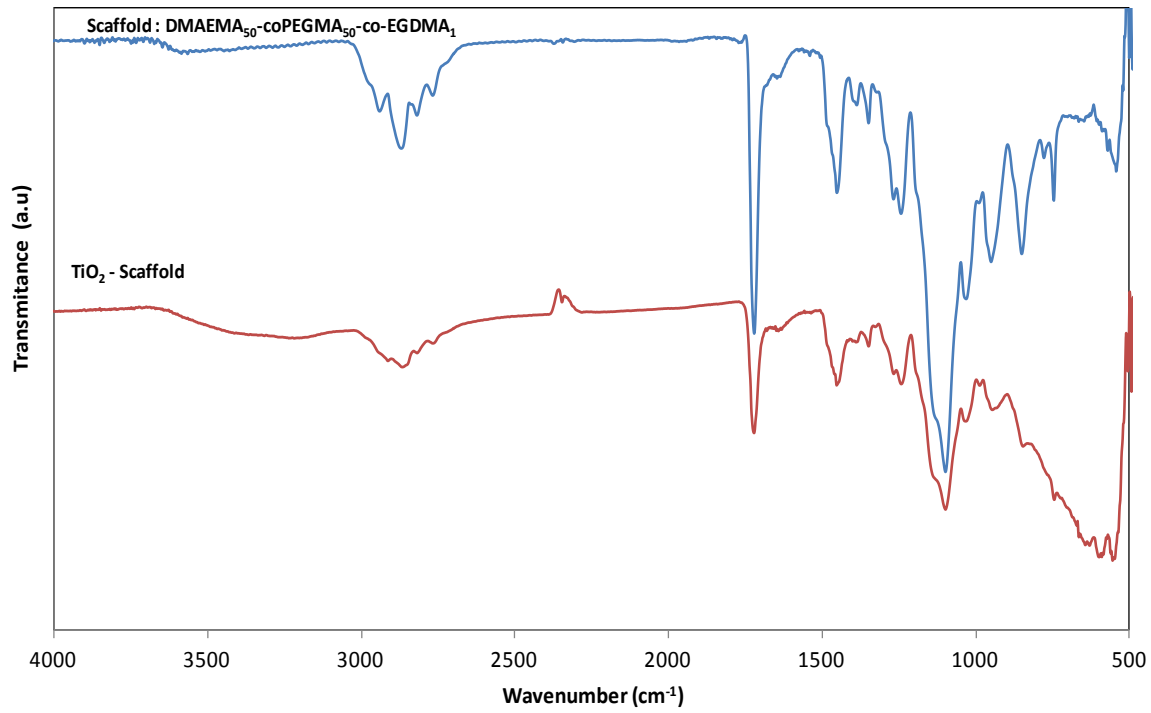

Figure 10. FTIR spectra of scaffold and as synthesized material prior to calcination. 


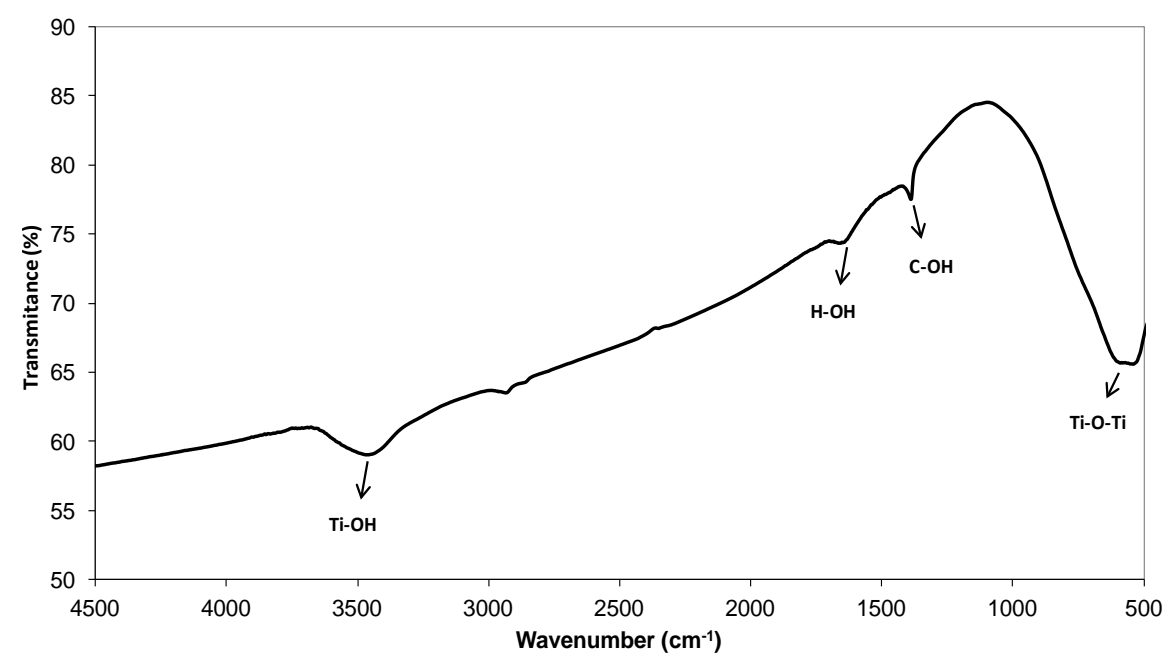

Figure 11. FTIR spectrum of modified titania after calcination at $500^{\circ} \mathrm{C}$ for $3 \mathrm{~h}$.

the presence of adsorbed water and structural hydroxyl groups showing surface hydroxylation.

The synthesized, modified and unmodified materials morphology was examined with scanning electron microscopy (SEM) as shown in Figure 12. As seen, the modified material exhibits a more loose texture when compared to the unmodified one.

It is shown that the modified samples exhibit similar morphologies, with an apparently more loose texture in comparison to the corresponding pristine samples. It is assumed that the slit shaped void spaces have occurred after the removal of the scaffolds and were shaped during the removal of the organic material. It is suggested that the creation of new Ti-O-Ti bonds leading to the synthesis of the titania lattice within the confines of the swollen gel, leads to the exclusion of water from that environment. Since it is the water molecules that cause the swelling, their removal led to shrinkage of the polymer network, which reduced the space available to the growing oxide lattice. This caused the extrusion of the precipitating solid from the inside of the gel, and may explain the observed morphology. The pristine samples seem to have a more rigid structure with less porosity.

The precipitation reaction in the swollen scaffold led, presumably, to the synthesis of the polymorph which is stable at room temperature, anatase, but the anatase to rutile phase transition is known to be facile. As titania crystallites accumulated in the constrained environment, constricting it even further, this provided the impetus for some of the crystallites to undergo an anatase to rutile phase transition. This took place on the surface of small crystallites, where $\mathrm{Ti}^{4+}$ and $\mathrm{O}^{2-}$ ions would be hydrated, and moved from an anatase structure arrangement to a rutile one, presumably with the assistance of hydrogen bonded water molecules. This would expose a new surface where further ion movement would be able to take place.

The modified materials showed a narrower pore size distribution, and a 

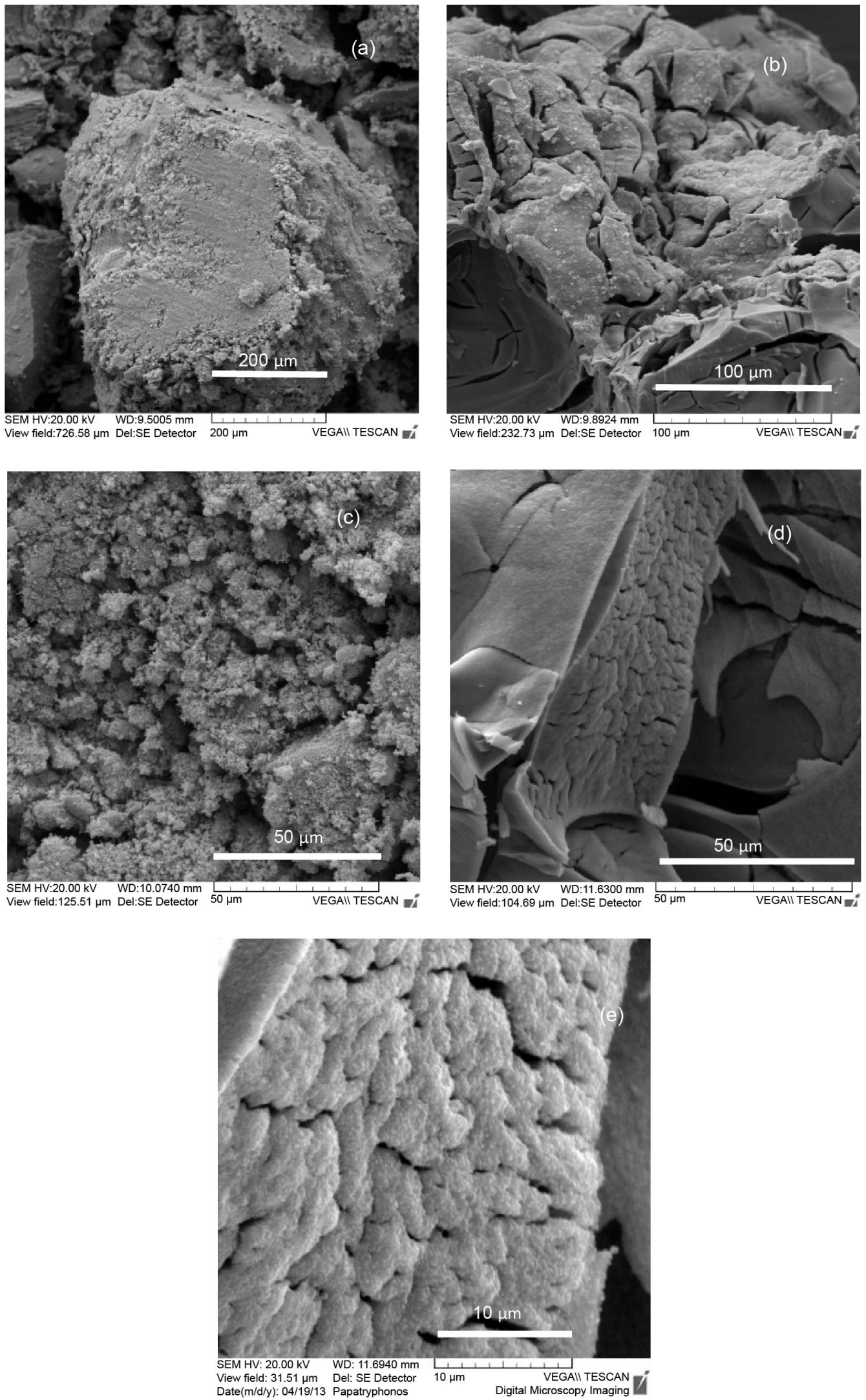

Figure 12. Scanning electron microscopy (SEM) images of unmodified (a), (c) and modified (b), (d) $\mathrm{TiO}_{2}$ calcined at $500^{\circ} \mathrm{C}$ for $3 \mathrm{~h}$. Image (e) as a magnification of $(\mathrm{d})$. 
marginally higher specific surface area. Additionally, the modified material contains both anatase and rutile polymorphs while the unmodified titania consisted of anatase phase only. Thus, the modification not only affects the porosity of the material but also offers a control on the polymorph of the product. The results provide a solid indication that the polymer network has a strong influence and in many cases improves the surface properties of the synthesized titania. The effect of the scaffold is attributed to the interaction between the growing titania particles and the polymer network.

\section{Conclusion}

Modified titania has been successfully synthesized with the use of the polymer

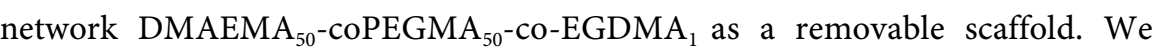
have also studied the precipitation of different metal oxides including ceria where the polymer network had a different effect on the porosity of the synthesized materials, showing that the scaffold-ceria interaction was different from the scaffold-titania [29]. This indicates that the precursor interaction with the polymer network also has a significant effect on the resulting materials. The interpretation of these results, points out that this scaffold provides us with control of the solids morphology. It was hoped that by increasing the cross-linker content of the gel would lead to a more organised environment, but that did not obtain. Given the fact that the polymer networks have a semi-regular structure, this gives a way of synthesizing mesoporous materials by adjusting the gels characteristics. We hope to use other swellable polymer networks with equally spaced cross-linking in order to synthesize better organised porous solids. This synthesis strategy provides us with better control of the solids morphology as we can control and adapt the gels properties according to our needs. A new family of porous materials with unique properties can be produced as this method can be potentially extended to many new fields of materials synthesis.

\section{Acknowledgements}

We appreciate the advice provided by Dr C.S. Patrickios of this Department.

\section{Declaration of Conflicting Interests}

The authors declared no potential conflicts of interest with respect to the research, authorship, and/or publication of this article.

\section{Funding}

We would like to thank the University of Cyprus for financial support, and the Cyprus State Scholarship Foundation for a studentship (Grant number 709 (14)) for CAP.

\section{References}

[1] Benjwal, P. and Kar, K.K. (2015) Simultaneous Photocatalysis and Adsorption 
Based Removal of Inorganic and Organic Impurities from Water by Titania/Activated Carbon/Carbonized Epoxy Nanocomposite. Journal of Environmental Chemical Engineering, 3, 2076-2083. https://doi.org/10.1016/j.jece.2015.07.009

[2] Borges, M.E., Sierra, M., Cuevas, E., et al. (2016) Photocatalysis with Solar Energy: Sunlight-Responsive Photocatalyst Based on $\mathrm{TiO}_{2}$ Loaded on a Natural Material for Wastewater Treatment. Solar Energy, 135, 527-535. https://doi.org/10.1016/j.solener.2016.06.022

[3] Fujishima, A., Rao, T.N. and Tryk, D.A. (2000) Titanium Dioxide Photocatalysis. Journal of Photochemistry and Photobiology C: Photochemistry Reviews, 1, 1-21. https://doi.org/10.1016/S1389-5567(00)00002-2

[4] Wang, H., Lin, T., Zhu, G., et al. (2015) Colored Titania Nanocrystals and Excellent Photocatalysis for Water Cleaning. Catalysis Communications, 60, 55-59.

https://doi.org/10.1016/j.catcom.2014.11.004

[5] Zhang, R., Elzatahry, A., Al-Deyab, S.S., et al. (2012) Mesoporous Titania: From Synthesis to Application. Nano Today, 7, 344-366.

https://doi.org/10.1016/j.nantod.2012.06.012

[6] Bahar, M., Gholami, M. and Azim-Araghi, M.E. (2014) Sol-Gel Synthesized Titania Nanoparticles Deposited on Porous Polycrystalline Silicon: Improved Carbon Dioxide Sensor Properties. Materials Science in Semiconductor Processing, 26, 491-500. https://doi.org/10.1016/j.mssp.2014.05.035

[7] Tantis, I., Dozzi, M.V., Bettini, L.G., et al. (2016) Highly Functional Titania Nanoparticles Produced by Flame Spray Pyrolysis. Photoelectrochemical and Solar Cell Applications. Applied Catalysis B: Environmental, 182, 369-374.

https://doi.org/10.1016/j.apcatb.2015.09.040

[8] Attipa, C. and Theocharis, C.R. (2009) Investigation of the Synthesis and Properties of Ternary V-Cu-Ce Oxides of Composition VxCuxCe1-2xO2. Adsorption Science and Technology, 9, 811-820. https://doi.org/10.1260/0263-6174.27.9.811

[9] Attipa, C. and Theocharis, C.R. (2007) Preparation and Characterization of Nanoporous Ternary Mixed Cerium Oxides. Studies in Surface Science and Catalysis, 160, 600-615. https://doi.org/10.1016/S0167-2991(07)80079-6

[10] Theocharis, C., Attipa, C., Hapeshi, E., et al. (2008) Study of the Crystallization of Nanoporous Mixed Metal Oxide Phases. Adsorption Science \& Technology, 26, 643-650. https://doi.org/10.1260/026361708788059848

[11] Tillirou, A. and Theocharis, C.R. (2006) Preparation of Mesoporous Ceria in the Presence of Non-Aqueous Phases. Studies in Surface Science and Catalysis, 160, 639-644. https://doi.org/10.1016/S0167-2991(07)80082-6

[12] Theocharis, C.R., Kyriacou, G. and Christophidou, M. (2005) Preparation and Characterization of Nanoporous Ceria Containing Heteroatoms, with and without a Matrix. Adsorption, 11, 763-767. https://doi.org/10.1007/s10450-005-6020-6

[13] Tillirou, A. and Theocharis, C. (2008) Synthesis and Characterization of Mesoporous Cerium Oxide Prepared Using an Organic Base and a Templating Agent. Adsorption Science \& Technology, 26, 687-692.

https://doi.org/10.1260/026361708788251385

[14] Pal, N. and Bhaumik, A. (2013) Soft Templating Strategies for the Synthesis of Mesoporous Materials: Inorganic, Organic-Inorganic Hybrid and Purely Organic Solids. Advances in Colloid and Interface Science, 189-190, 21-41. https://doi.org/10.1016/j.cis.2012.12.002

[15] Yuan, R., Fu, X., Liu, P., et al. (2006) Influence of Solvents on Morphology of $\mathrm{TiO}_{2}$ 
Fibers Prepared by Template Synthesis. Scripta Materialia, 55, 1003-1006. https://doi.org/10.1016/j.scriptamat.2006.08.015

[16] Suk, Y.H., Miyazawa, K., Honma, I., et al. (2003) Synthesis of Semicrystallized Mesoporous $\mathrm{TiO}_{2}$ Thin Films using Triblock Copolymer Templates. Materials Science and Engineering C, 23, 487-494. https://doi.org/10.1016/S0928-4931(02)00158-3

[17] Loryuenyong, V., Buasri, A., Srilachai, C., et al. (2012) The Synthesis of Microporous and Mesoporous Titania with High Specific Surface Area using Sol-Gel Method and Activated Carbon Templates. Materials Letters, 87, 47-50. https://doi.org/10.1016/j.matlet.2012.07.090

[18] Tang, G., Liu, S., Tang, H., et al. (2013) Template-Assisted Hydrothermal Synthesis and Photocatalytic Activity of Novel $\mathrm{TiO}_{2}$ Hollow Nanostructures. Ceramics International, 39, 4969-4974. https://doi.org/10.1016/j.ceramint.2012.11.093

[19] Miao, Y., Zhai, Z., He, J., et al. (2010) Synthesis, Characterizations and Photocatalytic Studies of Mesoporous Titania Prepared by Using Four Plant Skins as Templates. Materials Science and Engineering C, 30, 839-846.

https://doi.org/10.1016/j.msec.2010.03.020

[20] Shin, Y. and Exarhos, G.J. (2007) Template Synthesis of Porous Titania using Cellulose Nanocrystals. Materials Letters, 61, 2594-2597. https://doi.org/10.1016/j.matlet.2006.10.005

[21] Shamaila, S., Leghari Sajjad, A.K., Chen, F., et al. (2011) Mesoporous Titania with High Crystallinity during Synthesis by Dual Template System as an Efficient Photocatalyst. Catalysis Today, 175, 568-575.

https://doi.org/10.1016/j.cattod.2011.03.041

[22] Ji, L., Wang, Z., Li, Z., et al. (2008) Preparation of Aligned Titania Nanowires with an Aligned Carbon Nanotube Composite Template. Materials Letters, 62, 1979-1982. https://doi.org/10.1016/j.matlet.2007.10.055

[23] Hanaor, D.A.H. and Sorrell, C.C. (2011) Review of the Anatase to Rutile Phase Transformation. Journal of Materials Science, 46, 855-874. https://doi.org/10.1016/j.matlet.2007.10.055

[24] Rouquerol, F., Rouquerol, J., Sing, K.S.W., et al. (2014) Index. In: Adsorption by Powders and Porous Solids, Academic Press, London, 611-626.

[25] Li, Z., Yang, X., Wu, L., et al. (2009) Synthesis, Characterization and Biocompatibility of Biodegradable Elastomeric Poly(ether-ester urethane)s Based on Poly(3-hydroxybutyrate-co-3-hydroxyhexanoate) and Poly(ethylene glycol) via Melting Polymerization. Journal of Biomaterials Science, Polymer Edition, 20, 1179-1202. https://doi.org/10.1163/156856209X452944

[26] Li, Z., Yuan, D., Fan, X., et al. (2015) Poly(ethylene glycol) Conjugated Poly(lactide)-Based Polyelectrolytes: Synthesis and Formation of Stable Self-Assemblies Induced by Stereocomplexation. Langmuir, 31, 2321-2333. https://doi.org/10.1021/la504860a

[27] Mondal, S., Madhuri, R. and Sharma, P.K. (2015) PVA Assisted Low Temperature Anatase to Rutile Phase Transformation (ART) and Properties of Titania Nanoparticles. Journal of Alloys and Compounds, 646, 565-572. https://doi.org/10.1016/j.jallcom.2015.06.087

[28] Shin, H.S., Jo, C., Ko, S.H., et al. (2015) Mesoporous Titania with Anatase Framework Synthesized using Polyphenolic Structure-Directing Agent: Synthesis Domain and Catalytic Metal Loading. Microporous and Mesoporous Materials, 212, 117-124. https://doi.org/10.1016/j.micromeso.2015.03.033 
[29] Papatryfonos, C. and Theocharis, C.R. (2016) On the Use of Swellable Polymers as Structure Directing Scaffolds in Porous Solids Design. 7 th Panhellenic Symposium on Porous Materials, Ioannina, 2-4 June 2016, 169-170. 